\title{
The sedimentation plant at the Minworth Works of the Upper Tame Main Drainage Authority
}

\author{
J. B. MAYERS
}

\section{Mr J. B. Mayers}

Originally it was intended to use sulphate-resisting cement only in the 3 in. concrete sealing coat, but as the formation level was exposed, ground water tests were not very encouraging and so it was decided to use sulphate-resisting cement throughout.

61. The 'bleeding' of the concrete first occurred on a $2 \mathrm{ft}$ thick floor using aggregate $\frac{3}{4}$ in. down. About $\frac{1}{2}-\frac{3}{4}$ in. of clear water separated out on top preventing the surface from being polished and causing a dished surface. The Contractor then called in Mr E. H. Bate, whose paper in the Proceedings of December 1955 may be remembered, and who is an exponent of gap-graded concrete. He guided research on site, and ultimately a concrete was used which had aggregate $1 \frac{1}{2}$ in. single size and $\frac{3}{4}$ in. single size.

62. A mistake has occurred in Fig. 4 where the height of the floor just above the hopper should be given as 265.00 instead of $255.00 \mathrm{ft}$.

63. The competitive tender submitted by Messrs Grant, Lyon and Co. Ltd was - 11194120 . At a rough guess, as a result of the change of contractors, the job is likely to cost about $£_{\frac{1}{2}}$ million more.

\section{Mr M. S. Clements, University of Sheffield}

In some quarters, rectangular sedimentation tanks seem to have come to be looked upon as out of date. Mr Mayers has pointed out that they have the advantage of making full use of available space and, since land is likely to become even scarcer, there seems to be a future for tanks of this shape. The real difficulty with rectangular tanks, however, is the maintenance of even distribution across the breadth. $\mathrm{Mr}$ Mayers has rightly stressed the importance of this in his introduction.

65. In the design of the Minworth tanks a great deal of attention was obviously paid to this feature, but I wonder whether it is intended to test the effectiveness of the design in this respect by making measurements when the tanks are completed.

66. There are some tanks with rather similar inlets and, from modes and prototype velocity measurements in such a tank, carried out in a current research programme, a time ratio value of about 0.9 has been obtained. This is a measure of uniformity of flow across the tank breadth throughout the tank. It seems possible that the tanks under discussion could even improve on this, because such a great deal of effort has been put into uniformity of distribution.

67. I have to confess disappointment in one respect on reading the Paper, and that is in the paragraph where the tank dimensions are given. Mr Mayers mentions three criteria. One is a surface loading rating of $765 \mathrm{gal} / \mathrm{sq}$. $\mathrm{ft}$ per day. He also mentions retention of $6 \mathrm{~h} \mathrm{dwf}$, and goes on to say that the dimensions were 'derived empirically from the Authority's considerable past experience', viz. $250 \mathrm{ft} \times 160 \mathrm{ft} \times$ $10 \mathrm{ft}$. I feel that discussion of the relative importance of these variables would have added to the value of the Paper, since it will be read eagerly, I am sure, by designers in the future. Their conclusions, however, will be limited to the fact that on these figures it appears that rectangular sedimentation tanks work well if they are $250 \mathrm{ft} \times 160 \mathrm{ft} \times$ about $10 \mathrm{ft}$. I am sure that there are other sizes which would have the same order of efficiency.

Paper published: Proc. Instn civ. Engrs, 1969, 42 (Jan.) 39-56. 
68. Perhaps there may be in this design insufficient cross-sectional area to prevent scouring velocities. It appears that the mean velocity across the tank section is about $2 \mathrm{ft} / \mathrm{min}$, and, at the inlet, velocities of about $9 \frac{1}{2} \mathrm{ft} / \mathrm{min}$ would be expected. I wonder whether this aspect was considered.

69. I find it very interesting, however, to note that the surface loading rate chosen is higher than the figure often used for primary sedimentation. I would like to know from Mr Mayers whether any tests were made on the settling characteristics of the sewage in arriving at this figure. If so, could details of the range of settling velocities be made available? There is a dire shortage of information on these basic data which, because sewage is so variable, should receive greater study.

70. It would be valuable to know also what percentage removal of suspended solids was aimed at in design. Was the deciding factor difficulty of sludge treatment or reduction of load on the filters?

\section{Mr H. D. Manning, J. D. and D. M. Watson}

My first question is a rather general one. The storm water separation is at $\mathbf{3} \mathrm{dwf}$, which is a figure we seem to have heard before. In the early days, dry weather flows were of the order of 25 or $30 \mathrm{gal} / \mathrm{head}$, but today figures of 70 or $80 \mathrm{gal} /$ head are sometimes reached. I am also assuming, perhaps not accurately, that the pollution load has not changed greatly, at least not in that ratio. We are, therefore, now giving full treatment to a larger volume of very much weaker sewage.

72. There seems to be a case for a different approach. I wonder whether, in the calculation for these works, consideration was given to any particular pollution target in relation to the stream and whether any sophisticated argument was used as to the point of pollution at which the storm water should be treated. The rule of thumb basis of $3 \mathrm{dwf}$ does not by itself seem to be adequate. One would think that the criterion might be in terms of a certain number of gallons per head rather than $3 \mathrm{dwf}$.

73. A related point is the capacity of the storm water tanks. I did not detect any particular reasons for $4 \frac{1}{2} \mathrm{~h}$ detention. Did the Authors find any particular justification for this? A detention of $6 \mathrm{~h}$ used commonly to be suggested, but this had no particular meaning as far as I know. Were there any design factors which affected the determination of $4 \frac{1}{2}$ h capacity? Other speakers have referred to the proportions of the tanks. If we accept that the basic sedimentation theory leads us to only a plan area, then the only reason for a $10 \mathrm{ft}$ depth appears to be to give $6 \mathrm{~h}$ detention.

74. I do not suggest that it is an easy matter to determine exactly what the depth and the detention period should be, but $I$ wonder whether there is any particular basis for either $6 \mathrm{~h}$ or $10 \mathrm{ft}$ other than general experience. We know that minor disasters have occurred when people have used a depth of only $3 \mathrm{ft}$, basing it entirely on settlement theory, but there is still wide scope for variation on which research might seem appropriate.

75. In connexion with the difference between the storm water tanks and the sedimentation tanks, reasoned arguments are given for a slotted rather than a weir inlet on the sedimentation tanks, but I think that on the storm water tanks a weir inlet is adopted. I can think of reasons for this, but I wonder whether the Author would care to explain why the arguments used concerning the sedimentation tanks do not apply to the storm water tanks also.

76. I would be very interested to know how the scum removal apparatus is working in practice. A previous speaker has referred to various problems which have arisen, and I should be delighted to hear that the apparatus works better than most scum removal apparatus. Is it automatic in operation or is the side scraper under visual and manual control although motor-driven? Is there a tendency for scum to by-pass the moving plate and does the rotating slot give any trouble? A width of slot is not given. From the illustrations, it appears to be quite wide.

77. The use of expansion joints using a 1 in. thick cork insertion to break the 
structure into short bays is mentioned in $\S 56$, and it is stated that alternatively contraction gaps $2 \mathrm{ft}$ wide filled after 28 days have been adopted. I would be very interested to know the length of those short bays.

78. I understand from the figures quoted by the Author in introducing the Paper that the overall cost of the scheme could now be taken as being about $£ 3$ million, as against the original quotation of $£ 2 \frac{1}{2}$ million, the additional $£ 500000$ resulting from the failure of the original contractor to complete the work. It would be interesting to know what were the mechanical costs of the two different types of scraper and to have more cost information about the control system, the television system and the centralization of control of sludge removal.

79. The Author has referred to part of the panel showing the indicated levels in the various digesters so that the operator could see what he was doing. I should be interested to know what types of measuring device and level recorder were used. I have found that it is not quite as easy as it sounds to get an accurate determination of sludge level in a digester.

\section{Mr S. D. Myers, J. D. and D. M. Watson}

At first sight, the installation consists of eight sedimentation tanks each $250 \mathrm{ft}$ long and $160 \mathrm{ft}$ wide. This gives a length/width ratio of 1.56. Modern practice seems to favour the adoption of tanks with this ratio more in the order of 3 or 4 based more on experience than by reason of hydraulic theory. But a closer analysis of the tanks leads me to the conclusion that the ported wall running lengthwise down the tanks physically divides the large unit into two smaller ones, rather than acting purely as a support for the two halves of the sludge scraping mechanism. The resultant length/ width ratio of the smaller unit is a little greater than 3. This two-tanks-within-one appearance is emphasized by each half of the larger unit being provided with its own inlet arrangements, sludge scraping and scum skimming mechanisms and also television control of sludge removal. In fact, it is a complete unit on its own. I would be interested to hear what advantages were hoped to be gained from the adoption of the larger tank.

81. If I may state the main disadvantage as it appears to me, it is that, should it be necessary to carry out maintenance within the tanks - and this, I think, is probable owing to the use of a submerged moving-part sludge scraper mechanism-one eighth of the capacity will be lost during the period of maintenance. If a solid wall rather than a ported one had been built, only one sixteenth of the capacity need be out of line at any time. It would appear that the eight tanks have been designed as 16 smaller ones. Why has the benefit of the smaller unit been sacrificed?

82. In addition, the use of a ported wall is likely to cause turbulence along its length, upsetting what would otherwise be relatively quiescent settling conditions.

83. In connexion with the sludge scraping and scum skimming apparatus, the use of two scraper booms at opposite ends of the Flygt scraper channel is a rather neat arrangement. It appears, however, to have the disadvantage of sweeping the scum to the end of the tank remote from the sludge removal pipework. The waterborne scum is quoted as being swept away at the rate of $250 \mathrm{gal} / \mathrm{min}$ but through a $10 \mathrm{in}$. dia. pipe. This produces a velocity within the pipe when full of just over $1 \mathrm{ft} / \mathrm{s}$. It would appear that a build-up of grease within the scum removal pipework is almost inevitable, particularly at the end of each operation. Have the Board made provision for the removal of this grease, should it accumulate? The mixing of the scum with sludge from another tank should be beneficial, but the scum has a minimum of $100 \mathrm{yd}$ to travel before mixing with the sludge, and I question whether the quantity of water bearing it is capable of keeping it in suspension to that point.

84. With this length of tank, did the Board consider the use of a second boom following close behind the first to catch the sludge which might build up and flow back over the first boom? Is it envisaged that regular maintenance of the submerged 
rotating part of the scraping mechanism will be carried out, entailing the emptying of the tanks?

85. In connexion with the sludge removal arrangements, I feel from experience that the brilliance and sometimes genius of sewage works design lies not in its complexity, but in its simplicity. The use of television to control the removal of sludge from the tanks would appear to be a complicated solution, and an expensive one at that, to a rather difficult problem. The problem has been satisfactorily tackled at the Rye Meads Works of the Middle Lee Regional Drainage Scheme. It was noted by one of the staff of the Scheme that if sludge were projected horizontally, its trajectory would alter depending on the density of the sludge. If the sludge is projected into a chamber, as topwater begins to flow the line of the trajectory rises and at a predetermined level makes contact with a probe which completes a circuit actuating the control gear. A transparent wall to the chamber is provided so that a visual check may be carried out on the operation. The chamber is situated central to the batch of tanks and to the tank-operating gallery, the latter being on hand should manual operation of the valves be necessary in an emergency.

86. I should be interested to know the answers to the following questions. What were the alternative types of sludge density metering devices tested? What is the cost of the closed circuit television control system? In the event of a breakdown of the equipment when on-line, how is warning given to the operating staff at the tanks and how easy is it to operate the system manually, particularly at night?

87. Is there not some benefit to be derived from allowing some of the topwater at least to flow through the system in order to flush it out? Finally, how much of the bellmouth travel, nominally $5 \mathrm{ft} 9 \mathrm{in}$., actually can be used to induce flow of the sludge from the tanks?

\section{Mr J. E. James, Greater London Council}

Concerning the flow to the sedimentation tanks the Author states that some reduction in the width of the secondary ports can be made if they do not discharge approximately equal flows. How would any such streaming be discerned, and how would it be decided which ports to restrict and by how much? It would seem that considerable testing would be necessary, and it might be a case of trial and error.

89. The scraping mechanism is commendably simple, but I should like to know if there are any special problems with tensioning devices for the very long chains. The scumming arrangements are also very neat, but a great deal depends on the ability of the slotted withdrawal tube to clear the scum. If this does not come up to expectations, floating material will be left uncomfortably close to the settled sewage channel.

90. The desludging system is very interesting, and similar reasoning has led to the use of closed circuit television on the extensions to the Beckton Works of the Greater London Council. One major point of difference, however, is that at Minworth a single bellmouth valve serves three hoppers. Can a blockage in any one pipe, for example at a bend, be detected and cleared? If the cameras are placed in open chambers it will presumably be necessary to adjust the $m$ for day and night conditions. For this reason the chambers at Beckton are being provided with removable covers, and artificial lighting will always be used when the cameras are switched on. It would be interesting to know what grade of operator is to be responsible for desludging and, since the operation occupies only one half of two shifts per day, what other duties are to be given to him.

91. There must be a very good reason why bridge type scrapers were preferred for the storm tanks rather than the simple chain scrapers used in the sedimentation tanks. I would have thought that the latter would have been cheaper in capital cost as well as simplifying the maintenance problem by having the same machinery in all tanks.

92. Perhaps the Author could indicate what was the effect on the overall capital works programme of the unfortunate failure of the original contractor to.complete 
his work, and to what extent this affected the nominated sub-contractors for mechanical and electrical plant.

\section{Mr H. R. Oakley (Chairman)}

The complexity and sophistication of the work described in this Paper can be gauged from the unit cost, which on 1964 prices was $£ 70$ per 1000 gal of tank capacity and compares with costs adjusted to the same basis of about $£ 50$ at Leicester ${ }^{5}$ for soməwhat similar, but smaller tanks.

94. It would be of interest to know what proportion of the total cost is accounted for by the remote control arrangements, whether the Author feels this to be justified by the consequent saving of man power, and whether in retrospect he feels that any economy could have been made in this or other parts of the design, without detriment to the function and operation of the tanks.

95. Another matter of some interest is the relatively small capacity of the storm sewage tanks which on overspill give only $1 \mathrm{~h}$ retention at the maximum rate of flow through the tanks. What arguments were used to justify this departure from generally accepted standards and what effluent quality is required by the River Authority?

96. Reference was made in $\$ 19$ of the Paper to the balancing effect of the main sewers, but this is not an unusual feature on large systems, and although it would reduce the peak rate of discharge, it would not much reduce the total volume of storm sewage discharged to the works during a prolonged storm. I think that on works of this size and importance, careful consideration needs to be given to the storm flood profile, the response of the river to rainfall and the relative importance of pollution loads from the final effluent, from settled storm sewage and from overflows of storm sewage on the system.

\section{Mr E. W. Flaxman, Binnie \& Partners}

I should like to ask Mr Mayers a question concerning the television monitoring of the sludge withdrawal on the sedimentation tanks. In $\S 32$ he states that the telescopic bellmouth has a travel of $5 \mathrm{ft} 9 \mathrm{in}$. This appears to be a fairly generous figure and implies that, in some circumstances, a relatively large head will be required to get the sludge moving. Possibly this is related to the bends in the sludge withdrawal pipework which have already been mentioned. Clearly, once the sludge has started to move, a much smaller head will have to be used if the breakthrough of topwater is to be avoided.

98. Can the Author tell us what indication the operator will have of the amount by which the bellmouth has been lowered in any particular instance? Will he have some positive method of indication on the control panel, or will he have to rely on what he can observe on the television screen?

\section{Mr D. H. Hughes, J. D. and D. M. Watson}

I should like to comment on the fall of $1 \mathrm{ft}$ in the length of the sedimentation tank floor, which I assume applies also to the storm tank floors. I suspect that this may well have made a sizeable contribution towards the Contractor's financial difficulties. The effect of having a fall in the floor is that the wall reinforcing steel has to be of differing lengths along the length of the tank and repetitive form work cannot be used. These are significant features in construction costs.

100. What is gained by having the fall of $1 \mathrm{ft}$ in the length of the tank? It surely cannot be of any value in the movement of sludge along the length. It is said that it results, when the tank is empty, in rainwater flowing to the deeper end of the tank, but we saw from the illustrations that the tank floors were often wet and had accumulations of rainwater on them. Hence, it is not steep enough to achieve this result. My own view is that a level floor is the better answer for such large rectangular tanks.

101. This afternoon I was at the Deephams works of the Greater London Council 
and saw the operator de-sludging the primary tanks. The arrangement-except, of course, for the television set-up--is like that at Minworth, but each hopper has its own bellmouth, and the operator moves these as needed. He watches the sludge being discharged from them and has developed a kind of mystique in doing this, knowing from experience how to move around the bellmouths, raising and lowering them in the course of de-sludging.

102. Concurrently with this at Deephams, the operator is dealing with scum removal. This is at the inlet end of the tank and is essentially rather a personalized operation at this plant, where facilities are provided for removing from one side of the tank or the other depending on the build-up of the scum, the direction of the wind, etc. Only one man is required for all this, and $I$ have the feeling that he is far better employed in doing it where he can actually see the sludge and scum instead of watching it on television screens.

\section{Mr H. C. Balfour, D. Balfour \& Sons}

In $\$ \$ 4$ of the Paper the Author states that "The formation levels generally proved good, some soft spots being infilled with concrete'. The tanks extend over a vast area of land. Was any scientific method used for determining what is a soft spot? If so, was the Author satisfied with the results?

104. In the same paragraph the Author states: 'Because occasional high concentrations of sulphates had been found in the groundwater, a sealing coat of 3 in. concrete with sulphate resisting cement was used over the entire site.' Was this sealing coat also used around the vertical walls of the tanks, or was it employed only on the horizontal base?

\section{Mr D. A. Stewart, Cowdell \& Stewart}

I was most interested in that section of Mr Mayers's Paper which dealt with the concrete used in the works. Could the Author tell me how it came about that a gapgraded concrete was used, what proportions were employed and what sort of cube strengths were obtained.

106. I have advocated the use of gap-grading for many years now and have frequently used it with great success and economy. Some years ago I advised a contractor engaged on a large sewage works in North London. I designed his concrete mixes for the whole job. The mix used $1 \frac{1}{2} \mathrm{in}$. aggregate and had an $\mathrm{A} / \mathrm{C}$ ratio of 8 and $\mathrm{a} W / \mathrm{C}$ ratio of 0.58 . The finish was very good indeed, and the strengths were all in excess of $4500 \mathrm{lb} / \mathrm{sq}$. in. at 28 days with densities of $152 \mathrm{lb} / \mathrm{cu}$. ft. Concrete of this type is much easier to control and, where properly vibrated, a wall 10-12 ft high can be stripped in 2 or $3 \mathrm{~h}$ after placing.

\section{Mr Mayers}

Several speakers have commented on the general design of the tanks. Perhaps the simplest reply is that the Authority has had much experience over the years and, in particular, there are two papers which give a lead and, possibly, draw together some of the Author's experience. ${ }^{\theta, 7}$

108. As to the maintenance of scrapers and the possible lost capacity when a tank is out of action, one reason for having two booms instead of one is that the chains will rotate only $180^{\circ}$ instead of the full $360^{\circ}$.

109. Regarding tensioning the chains, it did not show up particularly well in the illustrations, but the lower sprocket at the hopper end has a device for tensioning. In any case, the chains run on angles which are pinned to the walls.

110. Mr Myers asked about grease removal and possible pipe blockage. The figures he quoted of amounts and velocities appeared to be right. We do not expect very much difficulty with pipe blockage, but it is the Board's usual precaution to 
equip a suitable pumphouse with a reciprocating pump which can remove such blockages.

111. I was asked a question about the types of sludge-metering device. The Board has tested the conductivity method, and this was not found to work. One reason is that variations in $\mathrm{pH}$ could be sufficient to upset the results. The gamma ray and ionization method was partly successful. Entrained gases produced erratic behaviour, and it was found that for short periods the results coincided with the results of samples, but the apparatus appeared to require constant supervision and, hence, it was not suitable for automation.

112. It was difficult to set the photoelectric cell to zero as it became clogged with sludge. It was tried at the Board's Yardley works and did not get a very good report there, although it was stated that it was quite good for locating a sludge blanket. So one comes back in this case to the human eye, which works extremely well.

113. On the question of bellmouth travel, I imagine that it will take about $2 \mathrm{ft} 6$ in. to $2 \mathrm{ft} 9 \mathrm{in}$. of depression of the bellmouth rim below top water level in the tank for normal starting of sludge movement. Once the sludge has started off, probably the bellmouth can be brought back to something like $10 \mathrm{in.} \mathrm{down.} \mathrm{It} \mathrm{is} \mathrm{quite} \mathrm{possible} \mathrm{that}$ the programme of sludging will not always be exactly regular, and it could be at a reduced rate over the weekend and, therefore, on Monday morning sludge might be quite tough. It was thought necessary to have this long travel of $5 \mathrm{ft} 9 \mathrm{in}$. from the sedimentation tanks and $6 \mathrm{ft} 3 \mathrm{in}$. on the storm water tanks just in case of trouble.

114. Mr James mentioned the way in which the entry velocity to the sedimentation tanks could be adjusted. It is quite obvious that a steady flow should be maintained, and probably this can only be obtained at an average flow, I would think, from the mere hydraulics of the system. Mr Daviss has assured me that tests will be carried out on these tanks when they come into operation to see how they will behave. I would suggest that such ports that have to be narrowed should be narrowed merely by tacking up bits of wood or something of that kind, unti] some kind of pattern has been achieved, when something more permanent could be fixed.

115. The question concerning the slotted withdrawal tube on the de-scumming device is what happens if it does not work. We simply hope that it does work, because that is the only way that the scum can get away. As far as I can see, the alternative would be to put the tank out of action, lower the water level and mix with the sludge on the bottom, which would be a terrible thing to have to do. These measures do work, however, and I do not think that the Board would have adopted this method if there was much chance of it not working.

116. Comment was made about there being three hoppers with their respective pipes coming to one sludging chamber with one camera. It is true that there is one $90^{\circ}$ bend on that pipework, and that is where the pipe coming up inside the hopper turns into the gallery, but that is a four-way junction and one can take a blank flange off to clean it out if necessary. The rest of the pipework is 10 in. dia. Each separate hopper has a valve on it, and the operator on the control panel will select his hopper, one of the three, to be covered by the one camera he wants, and he will put that camera's picture onto one of his monitors. He can put another monitor on another camera in the other half tank if he wishes.

117. Four monitors are provided because it would be essential to have three monitors going, i.e. three bellmouths discharging sludge at the same time, for two reasons. One is to get the job done in a reasonable time, and the other is that the pumps and the whole system at the other end for receiving the sludge would be geared to take a definite quantity. It will depend on how it works whether each hopper is desludged twice a day. As to the sizes and the calculations, my own view is that an effort should be made to discharge twice daily during weekdays and only once a day at weekends.

118. In that connexion, there was another question about labour. First, the man 
operating the panel and doing the remote control of sludge movement would obviously have to be a man of considerable skill, trained for this job. I would not care to guess what pay he will get, but he will not be the ordinary waterman-with-a-broom type. It seems to me that there will have to be a two-shift day, from 6 a.m. until midday, perhaps, and from midday until 10 or 11 p.m. each ordinary weekday. What will happen at nights or weekends, I do not know. There must always be somebody there.

119. At this point I would like to mention the cost of the scrapers. For the bridgetype scrapers, Templewood Hawksley quoted $£ 68000$ for six bridges. That works out at $£ 11300$ per tank. Sixteen of the Flygt type, or one to each half tank, two to a tank, were supplied by Farrer's for $£ 110000$, and this price included the scum concentrator. That works out at $£ 14000$ a tank. Therefore, for the storm water tanks we have a cost of $£ 11300$ and for the sedimentation tanks $£ 14000$, but that includes the scum concentrator.

120. Mr James also asked about the effect of bankruptcy. I thought that I had made the position fairly clear. The original cost was $£ 2 \frac{1}{2}$ million, and the final cost is likely to be $f 3$ million. The subcontractors were taken out of the original contract and the Board assumed responsibility for them, so that continuity of manufacture, and so on, for the specification was ensured.

121. Mr Manning asked about the quality of the effluent of the storm water tanks. As far as these new Minworth storm water tanks are concerned, may I remind you that the $14 \mathrm{ft}$ dia. sewer has an enormous unused capacity which, when the storm conditions warrant it, would cause it to act as a storm water tank. In fact, the capacity in that sewer is equal to the capacity of the tanks themselves. One can imagine that if the sewer ran full for long enough, if that is possible (it happens so seldom) and it filled the storm water tanks also, one would, in effect, have twice as many storm water tanks. However, the quality of the effluent which finally comes out of those tanks into the river is determined by the Trent River Board.

122. Mr Manning referred to the depth of the sedimentation tanks. All I can say is that the two papers in 1945 and 1947 to which I have referred ${ }^{6,7}$ and the Board's experiments at Yardley probably give the reason why this depth has been adopted.

123. I was asked about the weir in the storm water tanks compared with the slots in the sedimentation tanks. The operation is so different. One has to have a through invert on the sedimentation tanks to prevent accumulation of solid matter. The storm tanks are there to be filled and, when the storm has passed, for top water to be sent back through the system again. The weir method seems best to do that.

124. The scum operating system, to which $\mathrm{Mr}$ Manning referred, is automatic. Perhaps I did not make that clear. One cycle of the Farrer scraper consists in the chains going round for $180^{\circ}$ and stopping, the scum concentrator pushing the scum into the open tube and returning to base. This operation takes about $1 \frac{1}{4} \mathrm{~h}$. This can be set in a $24 \mathrm{~h}$ clock to conform to a predetermined pattern. If the scum is not normally moved away by one operation of the scum concentrator, it is possible to set it up for two operations.

125. Mr Manning mentioned also the expansion joints. These are $1 \mathrm{in}$., as he said, and break the structure into approximately $25 \mathrm{ft}$ panels. He asked about the cost of the scrapers, which 1 have given, and also about the type of depth indicator in the primary digestion tanks. This is a water-filled float column and, up till now, it has appeared to work satisfactorily.

126. The Chairman again mentioned the small retention period, and $I$ hope that what I have already said has dealt with that. I believe that the effluent quality for the storm water into the river has to be something like $150 \mathrm{ppm}$.

127. I was asked another question concerning the bellmouth travel and how blind the operator might be. In the sludge chamber, within sight of the camera, is a scale or some kind of indication so that the operator will see in his monitor not only the bellmouth but, beyond it, the fixed scale on the wall, which will tell him roughly where he is. 
128. Mr Hughes seemed to think that the slope on the floor caused the bankruptcy of the contractor. I could give him other and, probably, better reasons for this. In fact, it was almost predicted. I think it is fair to say that it is the Board's feeling that the slight slope on the floor helps the movement of sludge.

129. Mr Hughes made a remark which I must take up: that the man on the panel might go to sleep before his television sets. My view is that he will work extremely hard, at least at the beginning, until he gets a pattern to which he can work. The way in which I see it working is that he will decide which three hoppers are to be put into operation. He will start one going. As soon as he has got it going, he can turn to the next, and so on. It ought to take about 12-14 min on each hopper, so that on a time basis he would be able to make some kind of programme. Even though he has to move from right to left across the panel to get at his discharge valves, I think that with a little practice he ought to be able to do it fairly comfortably.

130. In answer to Mr Stewart, almost the first thick floor to be laid in this contract 'bled', so all materials mixing and placing methods were examined, especially for the sulphate-resisting cement, which was used owing to the nature of the ground water. Mr E. H. Bate, was called in to help.

131. Of nine trial mixes only two did not bleed, one with a water/cement ratio too low for workability, the other with an additive of unknown chemical composition possibly containing detergent. Of the remainder the most promising was the specified $\frac{3}{4}$ in. down but with the $\frac{3}{8}$ in. down removed. Thoughts turned to gap-grading and considerable experiments were done with $1 \frac{1}{2}$ in. aggregate. The best mix had single size $1 \frac{1}{2}$ in. but to meet Contractor's comments on workability some single size $\frac{3}{4}$ in. was included.

132. I give below the two mixes used, which proved very satisfactory, producing a very dense, economical concrete with excellent surface.

Replacing the $1: 2: 4$ nominal mix, for a $\frac{3}{4} \mathrm{cu}$. yd batch:

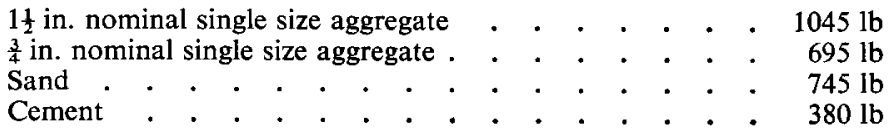

Water/cement ratio $=0.48$

Cement/aggregate ratio $1: 6.6$ approximately

Crushing strength $4500-5000 \mathrm{lb} / \mathrm{sq}$. in. at 7 days

Replacing the $1: 1 \cdot 6: 3 \cdot 2$ nominal mix, for a $\frac{3}{4} \mathrm{cu}$. yd batch:

$1 \frac{1}{2}$ in. nominal single size aggregate . . . . . . . $995 \mathrm{lb}$

$\frac{3}{4}$ in. nominal single size aggregate . . . . . . . . $663 \mathrm{lb}$

Sand . . . . . . . . . . . . . . . $710 \mathrm{lb}$

Cement . . . . . . . . . . . . . . . $450 \mathrm{lb}$

Water/cement ratio $=0.45$

Cement/aggregate ratio $1: 5 \cdot 4$ approximately

Crushing strength $5600-5900 \mathrm{lb} / \mathrm{sq}$. in. at 7 days

\section{References}

5. Beckett J. L. and OAKLey H. R. A combined scheme of sewage disposal and refuse composting in Leicester. Proc. Instn civ. Engrs, 1964, 29, 341-364.

6. Jenkins S. H., Hewitt C. H. and Roberts F. W. Balance of strength of sewage during sedimentation, Part 1. Proc. Inst. Sewage Purif. 1945, 1, 67-80.

7. Jenkins S. H., HewitT C. H. and Windsor C. E. Large scale experiments in sedimentation of sewage in rectangular tanks. Proc. Inst. Sewage Purif. 1947, 2, 67-92. 